\title{
Wanneer worden gemeenten gezien als waardevol?
}

\section{Lokale publieke waardecreatie door de ogen van lokale actoren ${ }^{*}$}

\author{
Scott Douglas \& Paul 't Hart
}

\begin{abstract}
Dit artikel verkent hoe we met behulp van het publieke waardeperspectief zicht kunnen krijgen op de kwaliteit van lokaal bestuur. Het publieke waardeperspectief beoordeelt de overheid niet op basis van algemene standaarden of benchmarks, maar via de oordelen van betrokken actoren. Deze benadering doet in potentie meer recht aan de unieke, lokale context van elke gemeente. Het publieke waardeperspectief wordt echter gecompliceerd door de veelheid aan verwachtingen die actoren hebben van bestuur en hun doorgaans negatieve vooringenomenheid ten opzichte van de overheid. Op basis van 71 interviews met verschillende actoren in zes gemeenten laten we zien hoe een publieke waardeperspectief op de vraag 'wordt er hier goed bestuurd?' uiteenlopende beelden oplevert, zelfs binnen gemeenten die door landelijke experts als succesvol worden gezien. Maar ook laten we zien welke verbindingen bestaan tussen deze beelden en hoe achter zuinige oordelen over het verleden optimistische ambities schuilgaan voor de toekomst.
\end{abstract}

\section{Moore's kruistocht}

Het publieke waardeperspectief is ontstaan als reactie op het bedrijfsmatig denken over de overheid van de jaren negentig. Volgens de grote inspirator van het publieke waardeperspectief Mark Moore (1995; 2013) wordt de betekenis van bestuurlijk handelen in die bedrijfskundige traditie verengd tot het enkel te beoordelen op basis van productie-targets, benchmarks en efficiëntie-normen. Moore wil de publieke aard van het bestuur weer centraal stellen, maar tegelijkertijd niet terugvallen in het bureaucratische denken waarbij overheden enkel worden beoordeeld op basis van protocollen en standaarden. In Creating Public Value (1995) betoogt Moore dat de overheid gericht moet zijn op het creëren van maatschappelijke meerwaarde, en in Recognizing Public Value (2013) stelt hij vervolgens dat deze publieke waarde vastgesteld kan worden door te kijken naar de oordelen van 'het publiek', ofwel de ervaringen vanuit verschillende actoren die zijn betrokken bij het beleid.

* $\quad$ S.C. Douglas, DPhil is universitair docent aan de Universiteit Utrecht.

Prof. dr. P. 't Hart is hoogleraar bestuurskunde aan de Universiteit Utrecht. Dit artikel is mede tot stand gekomen door onderzoeksfinanciering vanuit de Vereniging van Nederlandse Gemeenten. 
In theorie biedt het publieke waardeperspectief een positieve, constructieve kijk op het bestuur, maar in praktijk dreigt de ambitie te stranden op de tot nog toe gebrekkige operationalisatie ervan (Alford et al., 2017, Hartley et al., 2017) in verhouding tot klassieke instrumenten voor bestuurs- en beleidsevaluatie (zie bijvoorbeeld Behn, 2014). Volgens Moore en zijn navolgers moet publieke waardebepaling zijn geworteld in de oordelen van lokale actoren over de maatschappelijke baten van een bepaald programma of initiatief (zie Meynhardt, 2009; Page et al., 2015). Dat stuit echter op verschillende hindernissen.

Het eerste is dat actoren geen enkelvoudig en overkoepelend begrip hanteren als zij naar het functioneren van bestuurlijke daden en arrangementen kijken. De overheid moet bijvoorbeeld snel, zorgvuldig, flexibel en eerlijk zijn (Van der Steen, Scherpenisse, Van Twist et al., 2015). Ten tweede gaat het publieke waardeperspectief uit van een hypothetisch integraal oordeel vanuit 'het publiek', terwijl 'het publiek' in werkelijkheid bestaat uit een veelvoud van verschillende actoren en stemmen (Prebble, 2018). Ten slotte laat onderzoek zien dat veel actoren fundamenteel negatief tegenover de overheid staan en dat er dus geen fair waardeoordeel over specifieke programma's of projecten valt te verwachten (Marvel, 2015; Baekgaard \& Serritzlew, 2016).

In dit artikel verkennen we hoe constructief omgegaan kan worden met deze hindernissen, opdat het invloedrijke maar tot nog toe toch vooral heuristische denken van Moore en zijn navolgers kan worden vertaald in praktisch bruikbare tools, bijvoorbeeld voor wie op zoek wil naar voorbeelden van waardevol lokaal bestuur. Op basis van interviews met 71 verschillende actoren in zes gemeenten laten we zien hoe een publieke waardeperspectief inderdaad in eerste instantie botsende verwachtingen, gespleten groepen en terughoudende oordelen blootlegt, zelfs in gemeenten die door landelijke experts als succesvol worden gezien. Een nadere analyse van de resultaten laat ook zien dat voorbij deze botsingen ook verbindingen zijn te leggen tussen de actoren, dat negatieve oordelen niet zozeer voorkomen uit ontevredenheid over het heden als wel ambities voor de toekomst.

\section{Spanningen in het beoordelen van publieke waarde}

\section{Waarde versus waarden?}

Moore poneert een enkelvoudig, zij het geaggregeerd begrip van publieke waarde. Hij poogt in zijn public value account deze verschillende verwachtingen samen te brengen onder de noemer publieke waarde. Onder maatschappelijke baten neemt hij bijvoorbeeld de economische waarde van de publieke dienstverlening op naast de sociale impact op de gemeenschap. Onder kosten schaart hij de financiële lasten, maar bijvoorbeeld ook de opgeofferde vrijheid als gevolg van overheidsingrijpen. Hiermee worden deze verschillende waarden samengebracht in één overzicht, maar is nog niet duidelijk hoe ze tegen elkaar afgewogen moeten worden. Hoe kan bijvoorbeeld het belang van verkeersveiligheid verbonden worden met de wens voor snelle doorstroming? De roep om lage collectieve lasten met de even harde roep om excellente dienstverlening? Hood (1991) betoogde al dat er ver- 
schillende waardenfamilies zijn binnen de verwachtingen van de overheid. Moet de overheid integer en fair, effectief en efficiënt, of vooral robuust en adaptief zijn? Later werk rond 'competing values' (Cameron e.a. 2014) en verschillende handelslogica's (Van Loon, Leisink, Vandenabeele 2013) benadrukte keer op keer dat actoren meervoudige, vaak botsende verwachtingen hebben van de overheid.

Hét publiek versus de publieken

Publieke waarde is bij Moore 'wat het publiek waardevol vindt' (Moore, 1995). Dat klinkt goed, maar 'het publiek' of 'de samenleving' is in de praktijk altijd in meerdere of mindere mate gefragmenteerd (Prebble, 2018). De gemeenschap is verdeeld in verschillende actoren met verschillende belangen en rollen; van de cliënten die werken bij sociaal werkplaatsen tot de belastingbetaler in de gemeente, van de wethouder die politiek wil scoren tot de vrijwilligersorganisatie die knokt voor de eigen zaak.

Deze belangen van deze actoren hoeven niet noodzakelijkerwijs strijdig met elkaar te zijn, effectieve publieke managers kunnen win-winsituaties creëren voor verschillende actoren. Bryson, Crosby en Bloomberg et al. (2014) pleiten in hun model voor het meten van de waarde die voor de verschillende actoren en belanghebbenden wordt gecreëerd. Maar hoe kunnen de ervaringen van verschillende groepen met elkaar verbonden worden? Vallen marginalisering in het proces en schadelijke effecten voor een minderheid weg tegen empowerment en baten voor de meerderheid?

\section{Oordelen of vooroordelen?}

Het evalueren van het bestuur via de oordelen van actoren stuit op de negatieve vooringenomenheid jegens de overheid. Marvel (2015) laat in een experimenteel onderzoek zien dat Amerikaanse burgers publieke organisaties automatisch associëren met inefficiëntie en ineffectiviteit. Raadschelders (2019) beschrijft hoe er de Verenigde Staten in allerlei contexten veel scepsis heerst over de toegevoegde waarde van overheden en ambtenaren. Baekgaard en Serritzlew (2015) laten zien dat deze vooroordelen moeilijk zijn weg te nemen, doordat politici en burgers alleen maar informatie accepteren die aansluit bij hun bestaande denkbeelden. Als het deze actoren zijn die het bestuur gaan beoordelen, hoe groot is dan nog de kans op een eerlijk, laat staan een positief oordeel?

\section{Onderzoeksdesign}

Het onderzoeksdesign is gericht op het scherp krijgen van deze hindernissenin het beoordelen van waarde, maar ook in het blootleggen van mogelijke manieren om met de beperkingen om te gaan. De empirische data is verkregen uit een VNGonderzoeksrapport over waardevol lokaal bestuur (Van der Torre, Douglas, \& 't Hart, 2018). We kijken specifiek naar waardeoordelen over het lokale bestuur omdat het hier enerzijds mogelijk is overheden met vergelijkbare taken te vergelijken, maar er anderzijds juist behoefte is aan evaluatie-methodieken die lokale 
verschillen niet platslaan met landelijke benchmarks maar recht doen aan de plaatselijke behoeften en omstandigheden. We zetten hierbij in op drie verschillende beleidsdomeinen die gezamenlijk de verschillende rollen van de lokale overheid omspannen: lokaal woonbeleid in het fysieke domein; arbeidsparticipatie van mensen met beperkingen in het sociale domein; en democratische vernieuwing respectievelijk bevordering burgerparticipatie in het politiek-bestuurlijke domein.

We onderzoeken bewust gemeenten die het volgens landelijke experts goed doen om te onderzoeken of lokale actoren deze successen wel kunnen waarderen of dat zelfs hier de negatieve vooringenomenheid jegens de overheid domineert zoals beschreven in de theorie. We hebben daarom op elk van de drie beleidsdomeinen wetenschappelijke experts en landelijke beleidsmakers gevraagd gemeenten aan te wijzen die in Nederland relatief vooroplopen. Binnen deze set van zes gemeenten hebben we ingezet op een diversiteit van grote en kleine gemeenten, verdeeld over heel Nederland, en ze paarsgewijs vergeleken op het gebied van drie gemeentelijke opgaven: woonbeleid, arbeidsparticipatie van mensen met een afstand tot de arbeidsmarkt, en vernieuwing van de lokale democratie.

Per gemeente hebben we elf tot veertien semigestructureerde interviews uitgevoerd met bij de desbetreffende opgave betrokken wethouders, beleidsambtenaren, uitvoerders, netwerkpartners en vertegenwoordigers van de cliënten, bewoners of burgers. Alle interviews bespraken achtereenvolgens de definitie van waarde volgens de respondent in de besproken beleidsopgave, hun oordeel over de gecreëerde waarde en de praktijken die de waardecreatie volgens hen mogelijk had gemaakt. Deze gesprekken zijn volledig opgenomen en getranscribeerd. Daarnaast is de respondenten tijdens de interviews gevraagd een beredeneerd plus een cijfermatig oordeel te geven over de waarde van het gemeentelijk optreden - op een schaal van 1 tot 10 - en een cijfer voor specifieke waardendimensies daarbinnen (bijvoorbeeld de balans tussen kosten en baten, de rechtvaardigheid van de aanpak).

\section{De praktijk van publieke waardebepaling}

\section{Waarde versus waarden}

Alle interviews begonnen met de vraag welke publieke waarde de respondenten gerealiseerd zouden willen zien op het gekozen beleidsdomein. Zoals verwacht maakt deze vraag een grote vloed aan velerlei antwoorden los. Op de opgave arbeidsparticipatie liepen de antwoorden bijvoorbeeld uiteen van het kunnen voorzien in het eigen levensonderhoud door arbeidsgehandicapten tot het verlagen van de collectieve lasten door kosten van uitkeringen te verlagen, van het versterken van het gevoel van zelfstandigheid door de cliënten tot het verbinden tussen bevolkingsgroepen door deze samen te brengen op het werk. Ook noemden respondenten waarden die niet zozeer over de uitkomsten gingen als wel over het proces, zoals zorgvuldigheid en rechtvaardigheid in de omgang met cliënten. 
Tabel 1 Palet van maatschappelijke waarden, casus arbeidsparticipatie

\begin{tabular}{|c|c|c|}
\hline Materiële waarden & Immateriële waarden & Proceswaarden \\
\hline $\begin{array}{ll}\text { - } & \text { ledereen kan in eigen } \\
& \text { levensonderhoud } \\
\text { voorzien } & \\
\text { - } & \text { Zo min mogelijk uitke- } \\
\text { ringen uit publieke } & \text { middelen } \\
\text { - } \quad \text { Efficiënt inrichten } \\
\text { arbeidsparticipatie } \\
\text { - } \quad \text { Eerlijke concurrentie } \\
\text { tussen bedrijven }\end{array}$ & $\begin{array}{ll}- & \text { Solidariteit } \\
- & \text { Gevoel van zelfstandigheid } \\
- & \text { Gevoel van eigenwaarde } \\
- & \text { Plezier in het werk } \\
- & \text { Verbinding verschillende } \\
& \text { bevolkingsgroepen via werk } \\
- & \text { Helpen ondernemers om } \\
& \text { socialer te ondernemen }\end{array}$ & $\begin{array}{ll}\text { - } & \text { De mens centraal in het } \\
\text { - } & \text { beleid } \\
& \text { Maatwerk tussen beperking } \\
\text { individu en mogelijkheden } \\
\text { - } \quad \text { Samenwerken met partners } \\
-\quad \text { Zorgvuldigheid } \\
\text { - } \quad \text { Rechtvaardigheid }\end{array}$ \\
\hline
\end{tabular}

Sommige respondenten noemden tot wel tien verschillende waarden, terwijl anderen juist weer één waarde centraal zetten. Een gedeelte van de respondenten gaf aan niet zo bewust stil te staan bij de maatschappelijke opbrengsten van het beleid. Voor hen ging het om 'gewoon goed werk doen'. Ook stelden vooral verschillende ambtenaren onder de respondenten publieke waarde gelijk aan wat er formeel of beleidsmatig van de organisatie wordt verwacht, zoals 'het realiseren van de banenafspraak' voor arbeidsparticipatie.

De interviews produceerden dus een grote hoeveelheid aan verschillende waarden. De vraag is of deze diversiteit gelijk staat aan waardencomplexiteit en -conflict. Kijkend naar de verschillen tussen de waarden valt de complexiteit te reduceren door systematisch een onderscheid te maken tussen de verschillende soorten ambities. Tabel 1 geeft bijvoorbeeld een overzicht van de genoemde waarden, gesorteerd naar materiële, immateriële of procesuitkomsten (naar De Jong, 2016; Van der Torre et al., 2018). Materiële uitkomsten hebben betrekking op tastbare opbrengsten als het voorzien in eigen levensonderhoud van arbeidsgehandicapten of het verminderen van kosten voor de gemeentekas. Immateriële waarden gaan bijvoorbeeld over het gevoel van eigenwaarde voor werkzoekenden of het belang van solidariteit voor de samenleving.

Een ordening zoals in tabel 1 kan helpen de complexiteit hanteerbaar te maken, maar niet om deze geheel weg te nemen. Waar bijvoorbeeld een meer bedrijfsmatig perspectief op de overheid omgaat met complexiteit door de kwaliteit van bestuur te vertalen naar helderde doelstellingen en scherpe cijfers zodat er gemeten en afgerekend kan worden, is een toepassing van het publieke waardeperspectief gericht op het hanteerbaar en bespreekbaar maken ervan. In onze interviews met lokale actoren helpt het onderscheid om te zorgen dat mensen hun verschillende soorten ambities noemen, waarbij geen posten worden vergeten, of om preciezer aan te geven waar ze verbetering willen zien. Voor de arbeidsparticipatie bijvoorbeeld gaven de actoren in een van de gemeenten eerst aan 'gewoon niet tevreden te zijn', waarbij doorvragen blootlegde dat het niet zozeer ging om de materiële opbrengst van het beleid als wel het idee dat de processen van werkverdeling niet eerlijk verliepen. Hiermee hebben we nog geen eenduidig 'rapportcijfer', maar wel een gerichte indicatie waar verbetering mogelijk is. 
Vanuit deze ordening van waarde kan ook scherper bekeken worden in hoeverre er sprake is van waardenconflict, waarbij bijvoorbeeld de materiële waarde om publieke middelen te korten haaks staat op de immateriële waarde van solidariteit. In de interviews valt op dat de individuele actoren zelf al verschillende soorten waarden noemen, een en dezelfde respondent kan pleiten voor zowel harde efficiëntie en rechtvaardigheid in het proces. De meeste actoren geven ook direct aan te begrijpen dat het bestuur zal moeten laveren tussen deze ambities. Direct betrokken managers en cliëntvertegenwoordigers tekenen hierbij aan dat er veel schijnstrijd tussen de waarden zit. Een mensgerichte aanpak van arbeidsparticipatie gaat bijvoorbeeld juist goed samen met een goedkopere arbeidsparticipatie, omdat mensen dan beter geplaatst worden in passend werk. Vanuit deze perspectieven bestaat waardevol bestuur inderdaad uit het 'bedienen' van veel verschillende waarden, maar ook het bespreekbaar maken van de complexiteit, het laveren tussen ambities, of het kunnen vinden van verbindingen tussen waarden.

\section{Hét publiek versus de publieken}

De interviewronde laat zien dat 'het publiek' in de praktijk inderdaad bestaat uit een veelheid van 'publieken': where you stand depends on where you sit. Toch blijken de verschillende partijen wel degelijk overlap te vertonen in welke waarden zij nastrevenswaard achten. Op het beleidsdomein van wonen gaat het voor iedereen om een passend, kwalitatief goed en betaalbaar woonaanbod. Zowel wethouders, raadsleden, ambtenaren, burgers of belangengroepen pleiten in het gesprek voor een mix van materiële, immateriële en proceswaarden. Het verschil zit niet zozeer in de beoogde waarden als wel het perspectief op hoe die waarden er concreet uit moeten zien. Huurders concretiseren een kwalitatief goed woonaanbod in termen van huizen waar je 'twintig jaar fijn in kan wonen'. Woningbouwcorporaties concretiseren kwaliteit als huizen die de komende tachtig jaar 'duurzaam en onderhoudsvriendelijk' zijn.

Ook als het gaat om de beoordeling van de gerealiseerde waarde lopen de scheidslijnen anders dan verwacht. Natuurlijk waren raadsleden van oppositiepartijen doorgaans kritischer dan die van collegepartijen, maar bestuurders en ambtenaren zelf waren juist ook kritisch over de geleverde resultaten. Een ambtenaar gaf bijvoorbeeld zijn eigen initiatieven voor democratische vernieuwing slechts een krappe voldoende, omdat hij zelf vond dat er nog veel meer bereikt kon worden. 'Het publiek' als een eenduidige, heldere stem is in dit onderzoek een Mooriaanse fictie gebleken, maar evenmin dekt de categorische Wet van Miles (Where you stand ...) de lading. Actoren hebben deels voorspelbaar verschillende perspectieven bij het benoemen of toepassen van waarden, maar kennen ook gedeelde belangen, ambities en zorgen.

\section{Oordelen versus vooroordelen}

De geïnterviewden velden desgevraagd ook oordelen over het gevoerde gemeentelijk beleid op een relevante opgave. Met gemiddeld een 7- vallen die oordelen zuinig uit, zeker gezien het feit dat elke gemeente door landelijke experts was aange- 
wezen als koploper op het onderzochte beleidsdomein. Zelfs het woonbeleid van een gemeente die door experts wordt aangeduid als wereldwijde koploper, kreeg van de lokale actoren nog net geen zeven.

De teneur in de toelichting van de oordelen is 'het gaat goed, maar ...'. Zelfs de meeste ambtenaren en bestuurders hebben het eerder over onvolkomenheden dan over successen. Op het gebied van wonen roemt een publieke manager bijvoorbeeld de voortrekkersrol van de gemeente ('Ik denk dat toen het woord krimp nog niet uitgevonden was, wij al druk bezig waren met transformatie, met flats slopen en vervangende nieuwbouw') om er direct aan toe te voegen dat het sloopbeleid wellicht te ver is doorgeschoten.

Waardeoordelen over bestuurlijk optreden lijken al met al niet alleen een zaak van terugkijken maar ook van vooruitkijken te zijn. De internationale koploper in nieuwbouwwoningen moet zich volgens de lokale actoren nu bijvoorbeeld gaan richten op de volgende uitdaging: goed onderhoud en duurzaamheidsvergroting en leefbaarheid. Het woonbeleid moet zich niet meer alleen richten op 'de stenen' maar breder kijken naar de gemeenschap van mensen die in de wijken gaan wonen. De afgeronde projecten voor democratische vernieuwing leveren vooral de aanzet voor een nieuwe ronde van veranderingen en initiatieven. Waardevol bestuur is dus niet bestuur dat 'af' is of dat zijn doelen heeft 'behaald'.

\section{Discussie en conclusie}

Het publieke waardeperspectief is ontstaan als alternatief voor het in de ogen van zijn exponenten te bedrijfsmatig georiënteerde New Public Management, maar kent zo zijn eigen problemen met zich mee door zich te richten op de oordelen van betrokken actoren. Dit onderzoek onder zes gemeenten laat zien dat deze hindernissen moeilijk te vermijden zijn, maar ook dat de spanningen in praktijk niet zo scherp zijn. Hiermee biedt het publieke waardeperspectief een andere kijk op succesvol of waardevol bestuur. Dat is wellicht minder concreet en afrekenbaar dan de bedrijfsmatige en bureaucratische blik, maar doet wel meer recht aan de wensen en ervaringen van lokale actoren.

De opgehaalde waardendiversiteit staat niet noodzakelijkerwijs gelijk aan waardencomplexiteit of -conflict. De verschillende waarden kunnen worden geordend om de discussie te vergemakkelijken (Van der Torre et al., 2018). Verschillende waarden moeten tegelijkertijd worden gerealiseerd en er is begrip onder actoren voor de spanningen tussen alle ambities. Hiermee kan een publieke waardeperspectief op succesvol bestuur geen scherpe afgebakende lijst van concrete doelen opleveren, zoals een bedrijfsmatige insteek op bestuur beter zou lukken. Wel biedt de benadering inzicht in en een overzicht van het uitgebreide stelsel van ambities die actoren nastreven, inclusief de spanningen en verbindingen tussen die waarden. 
Een nadere beschouwing van 'het publiek' laat inderdaad zien dat er verschillende facties en standpunten bestaan (Prebble, 2018). Het is nuttig en belangrijk de verschillende verhoudingen tussen de verschillende groepen te zien, maar ook om te analyseren waar verschillen niet zozeer gaan over belangenstrijd als wel perspectiefverschillen. De scheidslijnen gaan eerder over verschillende perspectieven op het gedeelde belang, bijvoorbeeld tussen gemeente en woningbouwcorporatie, en ook de oordelen van verschillende groepen kunnen grotere overeenstemming vertonen dan een antagonistisch uitgangspunt zou vermoeden.

De bevindingen bevestigen ook dat actoren kritisch blijven over de prestaties van de overheid, in dit geval zelfs in zes gemeenten die het volgens landelijke experts uitstekend doen. De terughoudende oordelen komen echter niet noodzakelijkerwijs voort uit onvrede over het bestuur van nu, maar vanuit een ambitie voor meer in de toekomst. Er kunnen verlangens naar beleidsverbreding (bijvoorbeeld woonbeleid en sociaal beleid) en beleidsopvolging (bijvoorbeeld van nieuwbouw naar onderhoud, zie Wildavsky, 1979) achter steken. Bestuur kan dus waardevol worden geacht en tegelijkertijd worden uitgedaagd het nog beter te doen.

Deze inzichten kunnen van nut zijn bij het breder toepassen van het publieke waardeperspectief, maar moeten breder getoetst en systematischer onderzocht worden. De huidige bevindingen zijn slechts gebaseerd op een onderzoek binnen zes gemeenten, en zijn dus niet representatief voor alle gemeenten in Nederland of België, met daarbij gesprekken met 'slechts' twaalf actoren per gemeente, en dus niet representatief voor alle soorten stakeholders. Daarbij is gekeken naar drie beleidsdomeinen die weliswaar van elkaar verschillen, maar nog niet de hele diversiteit van werkzaamheden binnen het openbaar bestuur omvatten. Wellicht zijn er voor meer taakgerichte instellingen zoals de Belastingdienst of Rijkswaterstaat andere waardeverwachtingen dan voor brede overheden als de gemeente.

Het publieke waardeperspectief is niet de panacee die Moore en de zijnen ervan maken. Afgaan op de oordelen van actoren vraagt verdere analyse en een goed inzicht in de motivaties achter de oordelen. Net zoals dat de instrumenten voor een bureaucratische en bedrijfsmatige sturing jaren aan ontwikkeling nodig hadden, vereist een waarderingsmethodiek vanuit het publieke waardeperspectief verder onderzoek. Deze eerste analyse suggereert dat de problemen van het perspectief niet onoverkomelijk zijn en het daarmee een nuttig complement is op meer mainstream evaluatiebenaderingen bij het zicht krijgen op waarde(n)volle bestuurspraktijken.

\section{Literatuur}

Alford, J., Douglas, S., Geuijen, K., \& , Hart, P. 't. (2017). Ventures in public value management: Introduction to the symposium. Public Management Review, 19 (5), 589-604.

Baekgaard, M., \& Serritzlew, S. (2016). Interpreting performance information: Motivated reasoning or unbiased comprehension. Public Administration Review, 76(1), 73-82.

Behn, R.D. (2014). The PerformanceStat potential: A leadership strategy for producing results. New York: Brookings Institution Press. 
Bevan, G., \& Hood, C. (2006). What's measured is what matters: targets and gaming in the English public health care system. Public Administration, 84(3), 517-538.

Bovens, M., Schillemans, T., \& Hart, P.T. (2008). Does public accountability work? An assessment tool. Public Administration, 86(1), 225-242.

Bryson, J.M., Crosby, B.C., \& Bloomberg, L. (2014). Public value governance: Moving beyond traditional public administration and the new public management. Public Administration Review, 74(4), 445-456.

Cameron, K.S., Quinn, R.E., DeGraff, J., \& Thakor, A.V. (2014). Competing values leadership. London Edward Elgar Publishing.

Hood, C. (1991). A public management for all seasons? Public Administration, 69(1), 3-19.

Jong, J. de. (2016). Dealing with dysfunction: Innovative problem solving in the public sector. New York: Brookings Institution Press.

Loon, van, N.M., Leisink, P., \& Vandenabeele, W. (2013). Talking the talk of public service motivation: How public organization logics matter for employees' expressions of PSM. International Journal of Public Administration, 36(14), 1007-1019.

Marvel, J.D. (2015). Unconscious bias in citizens' evaluations of public sector performance. Journal of Public Administration Research and Theory, 26(1), 143-158.

Meynhardt, T. (2009). Public value inside: What is public value creation?. International Journal of Public Administration, 32(3-4), 192-219.

Moore, M.H. (1995). Creating public value: Strategic management in government. Cambridge, MA: Harvard University Press.

Moore, M.H. (2013). Recognizing public value. Cambridge, MA: Harvard University Press.

Page, S.B., Stone, M.M., Bryson, J.M., \& Crosby, B.C. (2015). Public value creation by cross-sector collaborations: A framework and challenges of assessment. Public Administration, 93(3), 715-732.

Prebble, M. (2018). Is 'we' singular? The nature of public value. The American Review of Public Administration, 48(2), 103-118.

Raadschelders, J.C.N. (2019). Challenges of governing democratic regimes: Public administration as counterweight to populism, partisanship, and rent-seeking. Paper for the annual conference of the American Society for Public Administration, March 8-12.

Steen, M. van der, Scherpenisse, J., \& Twist, M. van. (2015). Sedimentatie in sturing: Systeem brengen in netwerkend werken door meervoudig organiseren. Den Haag: NSOB.

Talbot, C. (2008). Measuring public value. London: The Work Foundation.

Torre, L. van der, Douglas, S., \& Hart, P. 't. (2018). Werken aan publieke waarde: Leren van en voor gemeenten. Universiteit Utrecht/Vereniging Nederlandse Gemeenten.

Wildavsky, A. (1979). Policy as its own cause. In A. Wildavsky, The art and craft of policy analysis (pp. 62-85). London: Palgrave Macmillan. 